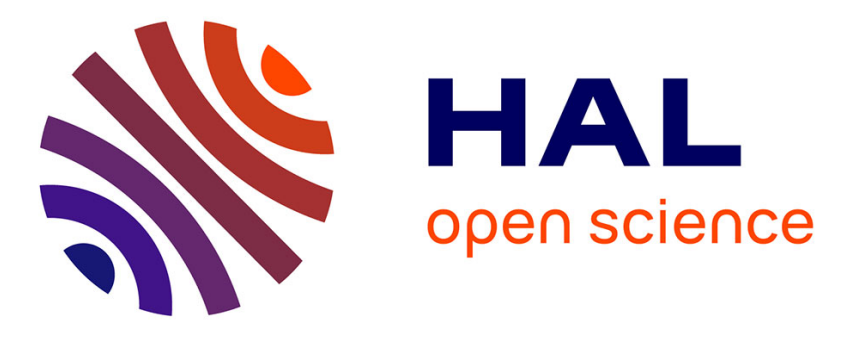

\title{
Influence of road structure on tyre/road contact in static conditions
}

Julien Cesbron, Fabienne Anfosso-Lédée, Honoré P. Yin, Denis Duhamel, Donatien Le Houedec

\section{- To cite this version:}

Julien Cesbron, Fabienne Anfosso-Lédée, Honoré P. Yin, Denis Duhamel, Donatien Le Houedec. Influence of road structure on tyre/road contact in static conditions: Numerical and Experimental Comparison. Road Materials and Pavement Design, 2008, 9 (4), pp.689-710. 10.1080/14680629.2008.9690145 . hal-01006977

\section{HAL Id: hal-01006977 \\ https://hal.science/hal-01006977}

Submitted on 10 Dec 2017

HAL is a multi-disciplinary open access archive for the deposit and dissemination of scientific research documents, whether they are published or not. The documents may come from teaching and research institutions in France or abroad, or from public or private research centers.
L'archive ouverte pluridisciplinaire HAL, est destinée au dépôt et à la diffusion de documents scientifiques de niveau recherche, publiés ou non, émanant des établissements d'enseignement et de recherche français ou étrangers, des laboratoires publics ou privés. 


\section{Influence of Road Texture on Tyre/Road Contact in Static Conditions}

\section{Numerical and Experimental Comparison}

\section{Julien Cesbron* — Fabienne Anfosso-Lédée* — Hai Ping Yin** Denis Duhamel** — Donatien Le Houédec***}

* Laboratoire Central des Ponts et Chaussées (LCPC)

BP 4129, F-44341 Bouguenais Cedex

\{julien.cesbron; fabienne.anfosso\}@lcpc.fr

** Université Paris-Est, UR Navier

École Nationale des Ponts et Chaussées

6-8 Avenue Blaise Pascal, F-77455 Marne la Vallée Cedex 2

\{yin;duhamel\}@lami.enpc.fr

*** GeM, École Centrale de Nantes

1 , rue de la Noё

BP 92101, F-44321 Nantes Cedex 3

Donatien.Lehouedec@ec-nantes.fr

ABSTRACT. This paper deals with the influence of road texture on normal pressure distribution for tyre/road contact in statics, within the framework of rolling noise prediction. A contact model is developed in statics where the tyre tread is modelled by an elastic half-space and the road surface by several perfectly rigid asperities. The problem is solved using a Two-scale Iterative Method (TIM) which is fast and efficient. The numerical results give high resolution contact patterns for real road surfaces. Predicted results are compared to contact pressures measured between a slick tyre and several road surfaces. The agreement is fairly acceptable by keeping in mind both the precision of the measurement device and the simplicity of the model. The best correlations are obtained for model surfaces composed of spherical punches and real road surfaces of moderated or high macro-texture. The results are less conclusive for road surfaces of fine macro-texture. The efficiency of the TIM at a tyre/road contact scale is an encouraging first step before introducing dynamical effects.

KEYWORDS: Tyre/Road Contact, Road Texture, Tyre Print, Pressure Measurements, Numerical and Experimental Methods 


\section{Introduction}

Tyre/road contact is an important issue for many road applications, such as skidding resistance, tyre noise emission and tyre rolling resistance. In the case of noise emission, the normal excitation of the tyre in the contact patch is the main cause of tyre vibration. Road texture has a great influence on this excitation and thus on noise emitted by the tyre/road interaction during rolling. Statistical correlations between tyre/road noise and road texture were first established by Sandberg and Descornet (1980) on a large variety of dense road surfaces. They found that road texture is correlated with tyre/road noise in two different frequency ranges: low frequency noise $(f<$ $1000 \mathrm{~Hz}$ ) is positively correlated with macrotexture (50 to $100 \mathrm{~mm}$ wavelengths) and high frequency noise levels $(f>1000 \mathrm{~Hz})$ are negatively correlated with small texture wavelengths ( 2 to $5 \mathrm{~mm}$ ). Similar correlations were obtained for road surfaces including porous asphalts (Anfosso-Lédée and Do, 2002, Klein et al., 2004) or specific road surfaces within the TINO project (La Torre et al., 1999). These statistical results are of great interest for identifying the part of the different texture scales in the generation of tyre/road noise. However, despite these correlations have been established for more than 20 years, the quantitative prediction of tyre/road noise from a given road surface is still an open issue. This is partly due to the difficulty of modelling the dynamic contact stresses between the road surface and the tyre tread during rolling.

Three main approaches were proposed in the literature for modelling tyre/road contact forces within the framework of tyre/road noise prediction. The first uses a Winkler bedding model in two (Kropp, 1992) or three dimensions (Hamet and Klein, 2000). The second is based on boundary element methods in two (Clapp et al., 1988, Klein et al., 2004) or three dimensions (Wullens and Kropp, 2004). The last one is a multi-asperity approach also in two (Fujikawa et al., 2005) or three dimensions (Sameur, 2004). In these different approaches, the tyre tread is often modelled by an elastic half-space in contact with a perfectly rigid road surface. For all these approaches, only normal contact forces are calculated since they are the main source of tyre radial vibrations responsible for noise emission. Thus friction is not taken into account in the models at the moment. Except the approach of Kropp (Kropp, 1992, Wullens and Kropp, 2004) that includes the dynamic response of the tyre belt using an orthotropic plate model, a recurrent hypothesis is that the contact during rolling is evaluated from several contact patches in statics or quasi-statics for successive time steps. Considering this last hypothesis, the resolution of tyre/road contact in statics becomes the main difficulty of the problem. For three dimensional models, the results are still limited to relatively large elements (Wullens and Kropp, 2004) or to asperities of simple shapes (Sameur, 2004), like spherical or conical indenters. Hence the prediction of normal contact pressures does not take into account the complexity of road surface texture at a fine scale. Moreover, the proposed models were not compared to experimental tyre/road contact patches measured in statics.

This study presents a simplified method for predicting the normal contact pressure for tyre/road contact in statics, which was developed by the authors within the framework of tyre/road noise prediction. The contact problem is solved at a fine scale 
and gives contact area and pressure distribution for real road surfaces in contact with a smooth tyre. The numerical results are compared with experimental contact data measured at the contact interface using a pressure sensitive device. After presenting the tyre/road contact model, some numerical results will be given and discussed. Then comparisons with experimental contact data are carried out before concluding remarks.

\section{Modelling tyre/road contact in statics}

The general hypotheses used for modelling the contact between the tyre and the road surface are illustrated in Figure 1. The problem is described using cartesian coordinates $(x, y, z)$.

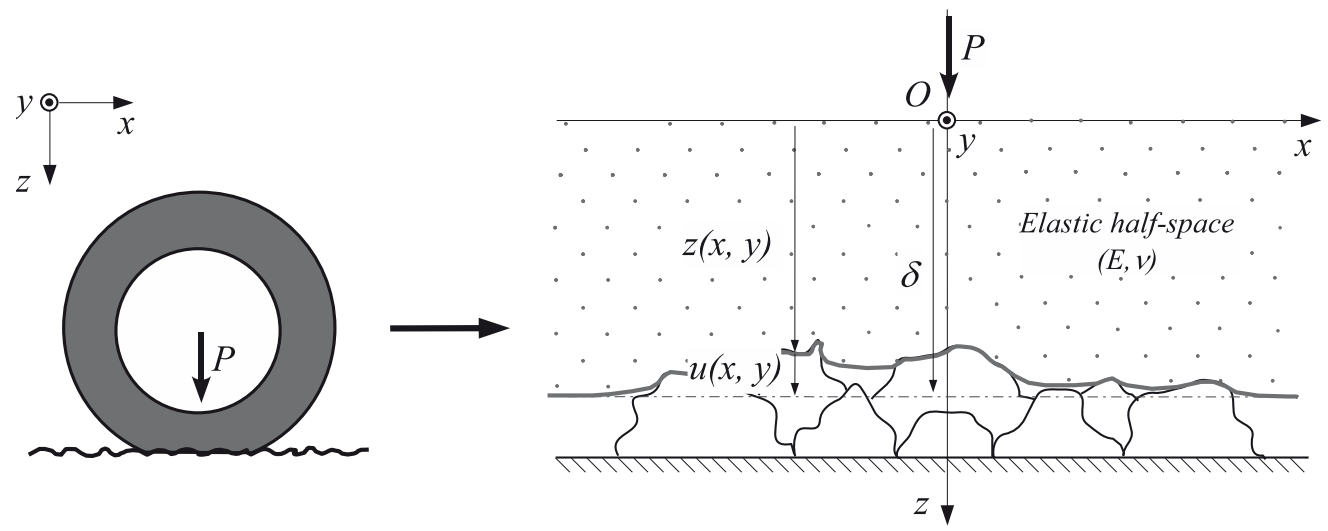

Figure 1. Contact between an elastic half-space and several rigid punches

First the tyre tread is modelled by a three dimensional elastic half-space with a Young's modulus $E$ and a Poisson's ratio $\nu$. This means that the complex structure of the tyre is not described in details and its stiffness is approached by the global value of the Young's modulus of the half-space. The geometric curvature of the tyre surface is taken into account in the model by adding it to the geometry of the road surface. Thus, the surface of the half-space modelling the tyre tread can be considered as perfectly flat.

Then the road surface is described by several perfectly rigid asperities with random shapes. It is assumed that the position and the geometry of each asperity is known from texture measurement for instance. Additionally the relation between the local load and the local penetration at the tip of each asperity is assumed to be known from analytical or numerical results, as it will be explained in Section 2.2. Note that the determination of an asperity is related to the scale at which the problem is considered, but the full contact problem can be solved by combining different texture scales.

Finally, the surfaces in contact are assumed frictionless, which means that there is no tangential tractions and only the normal pressure is taken into account in the contact area. In first approximation, the problem is solved assuming small strains. The total 
load $P$ applied on the tyre is known and the suspension is simply modelled by a pivot of longitudinal axis, allowing the tyre surface to rotate around the $\mathrm{x}$-axis and the total load to be well distributed at the contact interface in the transverse direction (y-axis).

\subsection{Formulation of the contact problem}

Considering the general hypothesis mentioned above, the classical contact problem of Boussinesq (1885) has to be solved. The unilateral contact problem is defined by the following equations:

$$
\begin{aligned}
& \forall(x, y) \in \Sigma, \quad u(x, y)=\iint_{\Sigma_{c}} p(\xi, \eta) T(x, y ; \xi, \eta) d \xi d \eta \\
& \forall(x, y) \in \Sigma_{c}, \quad u(x, y)=\delta-z(x, y) \quad \text { and } \quad p(x, y)>0
\end{aligned}
$$

where $\Sigma$ is the surface of the half-space, $\Sigma_{c}$ is the contact area, $u$ is the displacement at the surface of the half-space and $p$ is the normal pressure at the contact interface. Equation [1] gives the integral relation between $u$ and $p$, where $T$ is named the influence function of Boussinesq and is defined by:

$$
\forall\left(x, y ; x^{\prime}, y^{\prime}\right) \in \Sigma^{2}, \quad T\left(x, y ; x^{\prime}, y^{\prime}\right)=\frac{1}{\pi E^{*} \sqrt{\left(x-x^{\prime}\right)^{2}+\left(y-y^{\prime}\right)^{2}}}
$$

where $E^{*}=E /\left(1-\nu^{2}\right)$. Equation [2] contains two relations which have to be respected at the contact interface. The first one describes the fact that the surfaces of the contacting bodies can not penetrate. The distance $\delta$ is called the penetration and $z$ is the function characterizing the geometry of the indenting surface:

$$
\forall(x, y) \in \Sigma, \quad z(x, y)=z_{r}(x, y)-z_{t}(x, y)+\alpha y
$$

where $z_{r}$ is the surface of the road, $z_{t}$ the surface of the tyre tread and $\alpha$ is the angle of rotation around the longitudinal axis $(O, x)$ induced by the pivot ( $\alpha$ is assumed to be small). The second relation in Equation [2] is the compressive condition which means that the pressure in the contact area must be strictly positive (adhesion effects are not taken into account).

In the problem given by Equations [1] and [2], the unknowns are the contact area $\Sigma_{c}$, the pressure distribution $p$, the penetration $\delta$ and the angle $\alpha$. Then if the total load $P$ applied on the tyre is known, the equilibrium in statics gives the two following equations:

$$
\begin{aligned}
P & =\iint_{\Sigma_{c}} p(\xi, \eta) d \xi d \eta \\
0 & =\iint_{\Sigma_{c}} \eta p(\xi, \eta) d \xi d \eta
\end{aligned}
$$


Equation [5] corresponds to the equilibrium of the normal forces while Equation [6] results from the equilibrium of moments of the normal forces at point $O$. These equations are necessary for determining $\delta$ and $\alpha$.

\subsection{Resolution of the contact problem using a two-scale method}

The contact problem formulated above is solved using a Two-scale Iterative Method (TIM) which takes the advantage of the multi-asperity description of the road surface. First the contact force distribution at the tips of the asperities is calculated using an iterative scheme. This first step is called the macro-scale calculation step. Then, in a second step called micro-scale, the pressure distribution at the contact interface is estimated using the macro-scale contact forces as input data of a local Matrix Inversion Method (MIM) scheme (Johnson, 1985).

Recall that the classical MIM consists in dividing the surface of the half-space into identical square elements of side noted $h$ on which a constant pressure is assumed. Then Equation [1] becomes a vectorial equation of the form $\mathbf{A p}=\mathbf{b}$, where the pressure vector $\mathbf{p}$ is unknown, $\mathbf{A}$ is called the influence matrix and $\mathbf{b}$ is the known displacement vector. Usually the contact area is not known in advance and an iterative scheme is used for solving the contact problem. In the classical MIM algorithm, the global matrix $\mathbf{A}$ is first built from an overestimated contact area. Then the linear problem $\mathbf{A p}=\mathbf{b}$ is inverted and the pressure vector $\mathbf{p}$ is obtained. The negative pressure values are removed and a new problem is solved from the points with a positive pressure. This procedure is repeated several times until only positive pressures are found. When the problem involves a large number of points the MIM can become very time-consuming.

Here only a local MIM is involved at the micro-scale step, which makes the TIM more time efficient. In the following, the two calculation steps of the TIM are described in details.

\subsubsection{Load-penetration function for a single asperity}

The macro-scale calculation in the multi-asperity case was motivated by macroscale results for the contact between an elastic half-space and a single rigid asperity. In this case, the relation between the total load $P$ and the penetration $\delta$ can be written:

$$
P=C E^{*} \delta^{\gamma}
$$

where $C$ and $\gamma$ are constants depending on the shape and the size of the asperity. These constants are analytically known for axisymmetric punches (Sneddon, 1965), like flat-ended, spherical or conical punches.

In this study, the same relation as Equation [7] was found for a single asperity of random shape. An example is given on Figure 2 for a real road aggregate. The surface of the aggregate was finely measured and was then used as input of the classical MIM. The surface was divided into identical square elements of side $h=0.1 \mathrm{~mm}$ on which 
a constant pressure was assumed. For several values of $\delta$ the MIM gives the normal pressure distribution from which the total load $P$ is calculated by integration. Then the load-penetration relation was estimated (Figure 2, right) by linear regression (dotted line) on the numerical points $\left(\ln \delta, \ln \left(P / E^{*}\right)\right)$ (cross marks). In this example, the constant $C$ was equal to 2.29 and $\gamma$ was equal to 1.53. Similar results were found for other asperities of random shape.
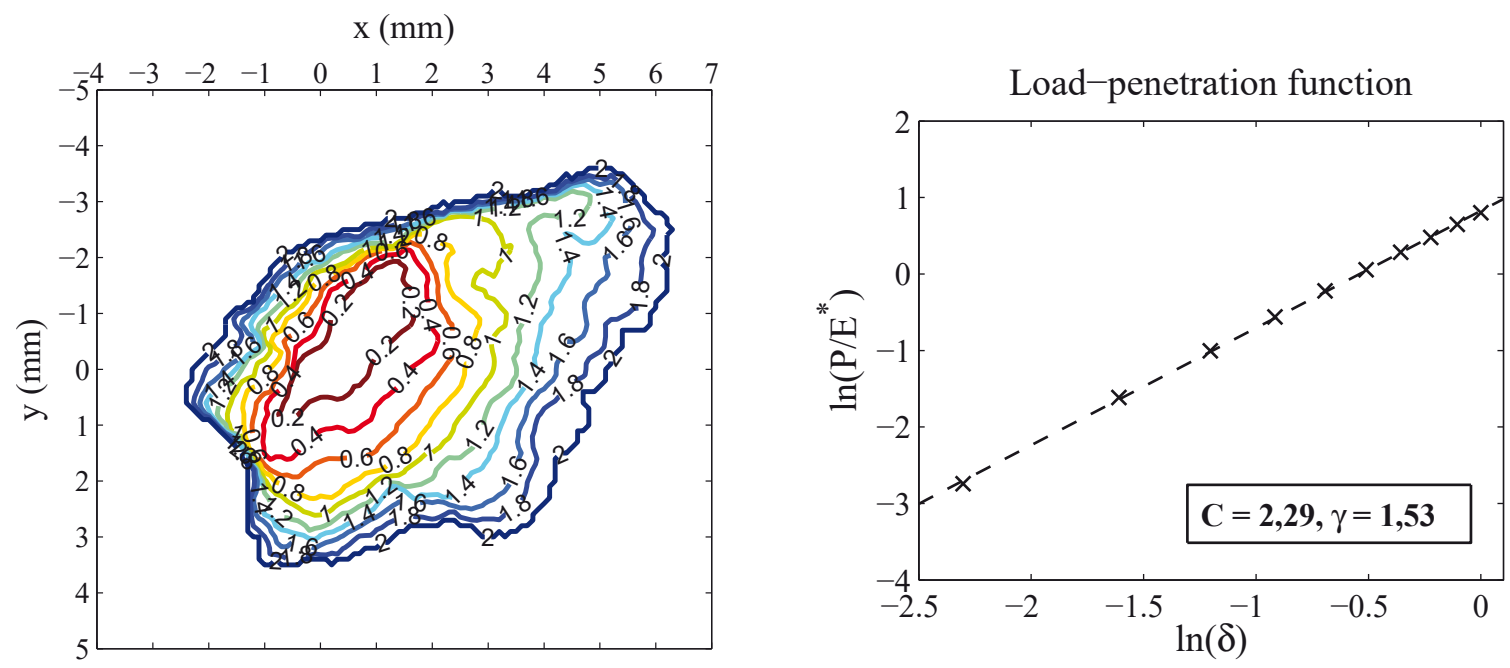

Figure 2. Measured isocurves and load-penetration function for a 3D real aggregate

\subsubsection{Macro-scale calculation: contact force distribution}

For macro-scale calculation, it is assumed that the relation between the local contact force $P_{k}$ and the local penetration $\delta_{k}$ is known for each asperity $k(k \in[1, N])$ and can be written as follows:

$$
\forall k \in[1, N], \quad P_{k}=C_{k} E^{*}\left[\delta_{k} H\left(\delta_{k}\right)\right]^{\gamma_{k}}
$$

where $C_{k}$ and $\gamma_{k}$ are constants depending on geometry of the asperity and $H$ is the Heaviside's function which ensures that the contact force is null when $\delta_{k}$ is negative, corresponding to no contact on the asperity.

Then, from Equations [1] and [2], the displacement on the punch $k$, noted $u_{k}$, inside the local contact area $\Sigma_{c k}$ can be written:

$$
u_{k}(x, y)=\delta-z(x, y)-\sum_{\substack{l=1 \\ l \neq k}}^{N} \iint_{\Sigma_{c l}} p_{l}(\xi, \eta) T(x, y ; \xi, \eta) d \xi d \eta
$$

Assuming that the distance between the asperities is large enough in comparison with the size of the local contact areas, the influence function of Boussinesq remains almost constant for each asperity $l$ interacting on the asperity $k$. Thus the influence function can be estimated from its value at the tips of asperities $k$ and $l$ :

$$
T_{k l}=T\left(x_{k}, y_{k} ; x_{l}, y_{l}\right)=\frac{1}{\pi E^{*} \sqrt{\left(x_{k}-x_{l}\right)^{2}+\left(y_{k}-y_{l}\right)^{2}}}
$$


Consequently, Equation [9] becomes:

$$
u_{k}(x, y) \simeq \delta-z(x, y)-\sum_{\substack{l=1 \\ l \neq k}}^{N} T_{k l} P_{l}
$$

and knowing that the local penetration $\delta_{k}$ corresponds to the displacement at the summit of the punch $k$ of coordinates $\left(x_{k}, y_{k}, z_{k}\right)$ :

$$
\delta_{k}=u_{k}\left(x_{k}, y_{k}\right)=\delta-z_{k}-\sum_{\substack{l=1 \\ l \neq k}}^{N} T_{k l} P_{l}
$$

Replacing $\delta_{k}$ in the system of Equations [8] by the expression given in Equation [12] leads to a system of $N$ non-linear equations of $N+2$ unknowns which are the $N$ contact forces $P_{k}$, the global penetration $\delta$ and the pivot angle $\alpha$. Then the problem can be solved using the equilibrium Equations [5] and [6], which expression at the macro-scale is:

$$
\begin{aligned}
& P=\sum_{k=1}^{N} P_{k} \\
& 0=\sum_{k=1}^{N} y_{k} P_{k}
\end{aligned}
$$

This problem of non-linear equations is solved using the iterative method of NewtonRaphson and finally gives the contact force distribution at the tip of each punch, the penetration $\delta$ and the angle $\alpha$.

\subsubsection{Micro-scale calculation: contact pressure distribution}

From macro-scale results, the normal pressure distribution at the contact interface can be approximated using a local MIM (Johnson, 1985) at the scale of each individual punch. On each asperity, the interface is discretized into square identical elements of side $h$ and coordinates $\left(x_{k_{i}}, y_{k_{i}}\right)$ on which the pressure is assumed constant. Then the micro-scale contact problem on the $k^{\text {th }}$ punch can be discretized and written as:

$$
\begin{gathered}
\forall i \in\left[1, n_{k}\right], \quad u_{k_{i}}=\sum_{j=1}^{n_{k}} A_{k_{i j}} p_{k_{j}} \\
\forall\left(x_{k_{i}}, y_{k_{i}}\right) \in \Sigma_{c k}, \quad \delta_{k}-u_{k_{i}}-z_{k_{i}}=0 \quad \text { and } \quad p_{k_{i}}>0 \\
P_{k}=h^{2} \sum_{i=1}^{n_{k}} p_{k_{i}}
\end{gathered}
$$


where $n_{k}$ is the number of elements on the $k^{\text {th }}$ punch and $A_{k_{i j}}$ is the influence coefficient between elements $i$ and $j$. This is analytically calculated from the following expression:

$$
A_{k_{i j}}=\int_{y_{k_{j}}-h / 2}^{y_{k_{j}}+h / 2} \int_{x_{k_{j}}-h / 2}^{x_{k_{j}}+h / 2} T\left(x_{k_{i}}, y_{k_{i}} ; \xi, \eta\right) d \xi d \eta
$$

Equations [16] and [17] lead to a local matrix inversion problem of the form $\mathbf{A}_{k} \mathbf{x}_{k}=\mathbf{b}_{k}$, with the unknown vector $\mathbf{x}_{k}=\left\{p_{k_{1}}, \cdots, p_{k_{n_{k}}}, \delta_{k}\right\}^{T}$, the vector $\mathbf{b}_{k}=\left\{-z_{k_{1}}, \cdots,-z_{k_{n_{k}}},-P_{k} / h^{2}\right\}^{T}$ and the influence matrix $\mathbf{A}_{k}$ such as:

$$
\mathbf{A}_{k}=\left(\begin{array}{cccc}
\mathrm{A}_{k_{11}} & \cdots & \mathrm{A}_{k_{1 n_{k}}} & -1 \\
\vdots & \ddots & \vdots & \vdots \\
\mathrm{A}_{k_{n_{k} 1}} & \cdots & \mathrm{A}_{k_{n_{k} n_{k}}} & -1 \\
-1 & \cdots & -1 & 0
\end{array}\right)
$$

This problem can be solved using the classical MIM on the punch $k$ for a known loading force $P_{k}$. Then the local pressure vector on punch $k$, noted $\mathbf{p}_{k}$, is obtained. When the calculation is completed on each punch, the pressure distribution at the contact interface is estimated and is given by the global pressure vector $\mathbf{p}=\left\{\mathbf{p}_{1}, \cdots, \mathbf{p}_{k}, \cdots, \mathbf{p}_{N}\right\}^{T}$. In a first approximation, $\mathbf{p}$ gives a good prediction of the pressure distribution in the contact area. It can be improved by the introduction of an iterative process that will not be described here but can be found in (Cesbron, 2007).

\subsection{Example of numerical results for tyre/road contact}

The TIM approach was successfully compared with the classical MIM (Johnson, 1985) in a preliminary work (Cesbron, 2007). For small surfaces composed of seven identical punches at the same height (spherical, conical or flat-ended) the TIM gave the same results as the classical MIM, taken as a reference method. For these configurations, the convergence of the TIM in terms of CPU time is faster than the classical MIM by a factor of more than 10. This ratio is even higher when the number of punches increases (a factor of 70 was observed in the case of 24 spherical punches). This makes the TIM a suitable tool for the prediction of normal contact forces between a tyre and a rough road surface including a large amount of asperities. To demonstrate the capacity of the method, calculations were performed at the scale of a real tyre print on a road surface. For a given road surface, the calculation is divided in three main steps as illustrated in Figure 3.

The road surface is described in the cartesian coordinates $(X, Y, Z)$. The preprocessing step consists in the identification of the asperities from a three-dimensional texture of the surface obtained with a micro-measurement optical device. The measured surface is an array of 955000 coordinates distributed on a $200 \mathrm{~mm}$ by $191 \mathrm{~mm}$ 


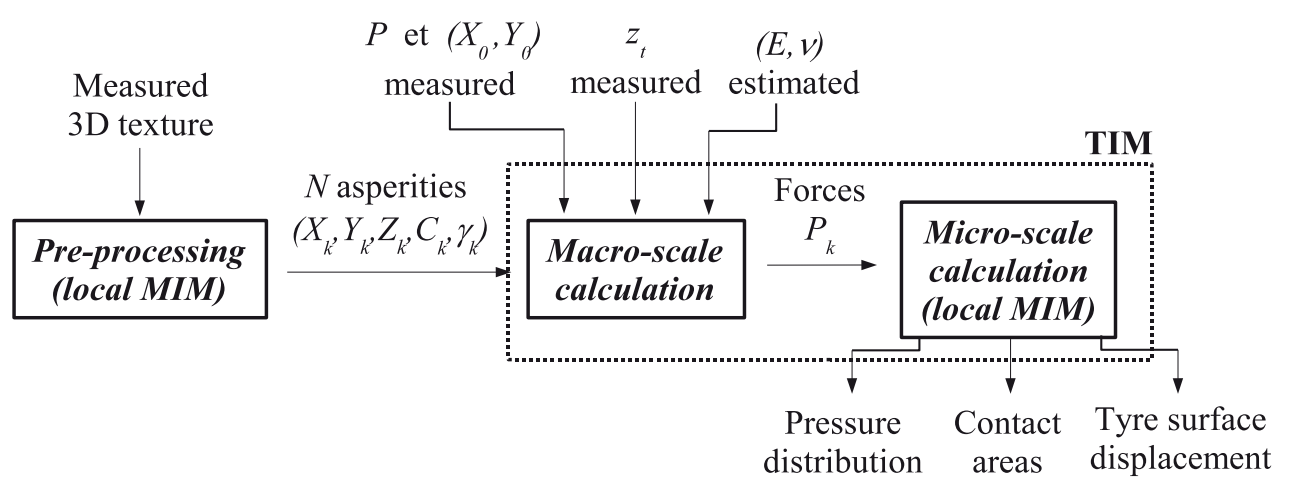

Figure 3. Calculation overview of tyre/road contact pressures in statics

rectangular surface with a spacing of $0.2 \mathrm{~mm}$. This data set is then pre-processed by a labelling procedure that identifies and numbers the asperities. The procedure is described in detail in Appendix A. Each identified asperity can include different texture scales which are directly related to the roughness measured on the surface. Then the load-penetration function is determined for each identified punch by the numerical approach described in Section 2.2.1. Finally the surface is composed of $N$ asperities for which the coordinates of the tip $\left(X_{k}, Y_{k}, Z_{k}\right)$ and the coefficients $C_{k}$ and $\gamma_{k}$ of the load-penetration function are known.

Knowing these surface parameters, the macro-scale calculation step of the TIM can be performed. Additional input parameters such as the total load $P$ applied on the wheel, the Young's modulus $E$ and the Poisson's coefficient $\nu$ of the tyre material are needed in the model. The curved geometry of the tyre $z_{t}(x, y)$ and the position $\left(X_{0}, Y_{0}\right)$ of the point where the total load $P$ is applied are also introduced in the model. Then the macro-scale calculation gives the force distribution on all the defined punches. Finally, the local MIM is applied on each punch in order to get the pressure distribution and the contact areas at the micro-scale.

In Figure 4, examples of numerical results in terms of pressure distribution (right column) are shown for three different surfaces (left column). The first one on the top is a periodic model surface composed of identical spherical punches of radius equal to $5 \mathrm{~mm}$. The second one in the middle is a real Dense Asphalt Concrete road surface with aggregate maximum size of $10 \mathrm{~mm}$. The last one at the bottom is a real Porous Asphalt road surface with aggregate maximum size of $10 \mathrm{~mm}$. A total load $P$ of 2950 $\mathrm{N}$ is applied on the surfaces by a slick tyre of diameter $57 \mathrm{~cm}$ and width $186 \mathrm{~mm}$. The Young's modulus of the half-space used to model the tyre tread is $E=2.4 \mathrm{MPa}$ and the Poisson's coefficient $\nu$ is 0.5 , which is common for rubber-like materials. The first contact pattern was obtained in about 10 minutes (CPU time) while the two others for real road surfaces were obtained in less than one hour (CPU time) on a standard computer (PC Pentium 4/3.40 GHz).

For the three surfaces, the results of Figure 4 give realistic contact prints at a fine texture scale and the contact pressure values are within the expected range. The ratio between the mean radius of the local contact areas and the mean distance separat- 
Periodic surface composed of spherical punches
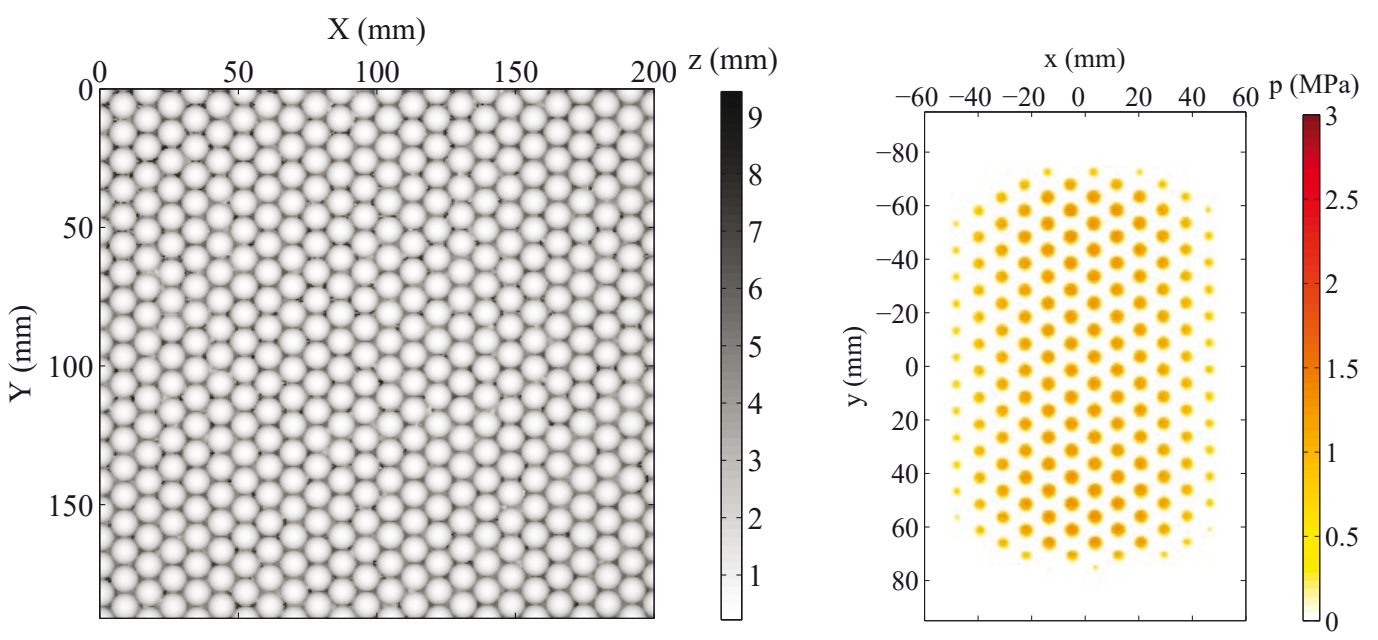

Dense Asphalt Concrete 0/10
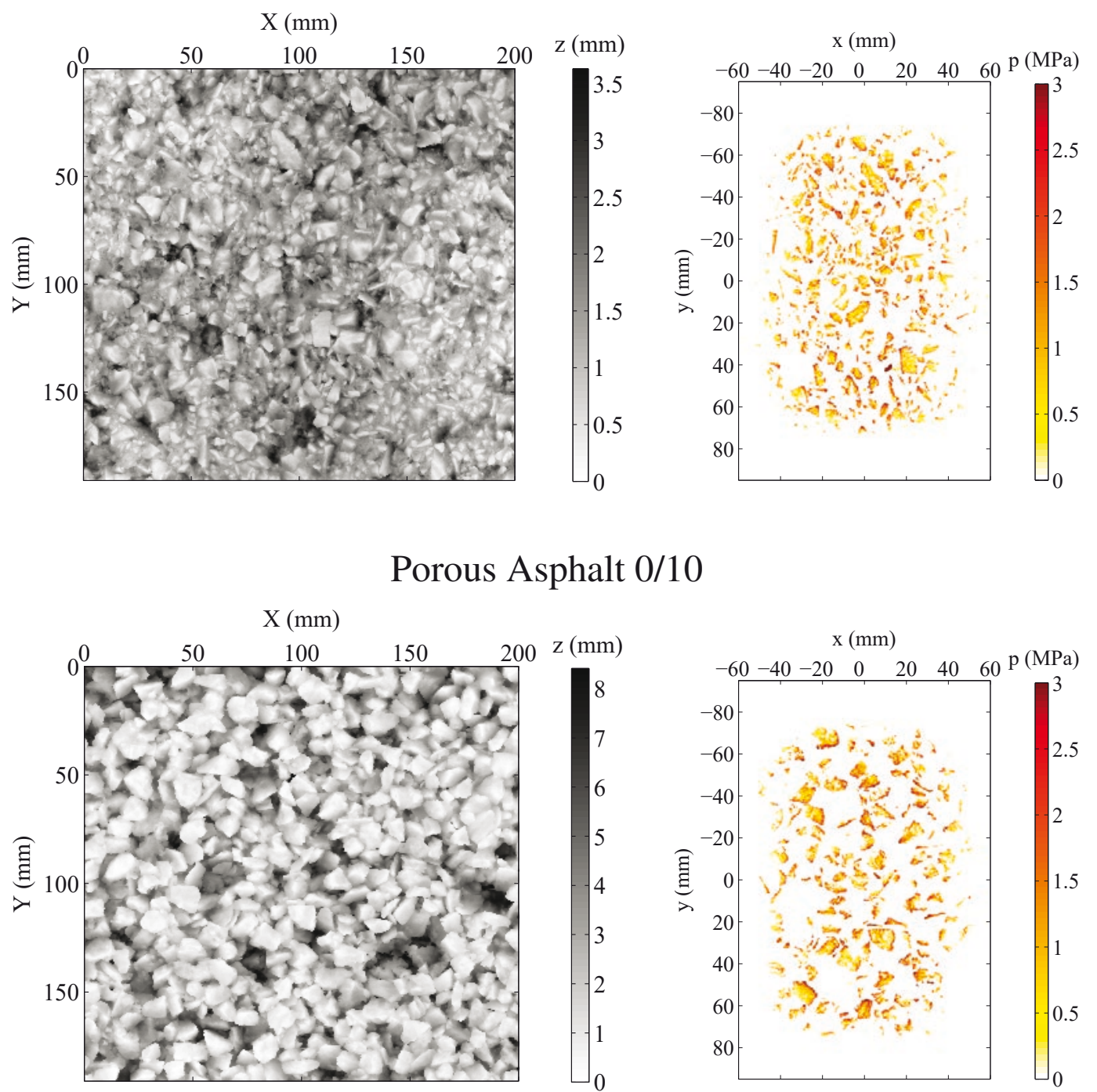

Figure 4. Measured 3D texture (left) and calculated pressure distribution in tyre prints (right) for three surfaces 
ing the asperities is in the order of 5. This is enough for treating the asperities as sparse enough at the macro-scale and as isolated at the micro-scale. The mean strain within the contact area can be assessed by dividing the mean contact pressure $p_{m}$ by the Young's modulus $E$. This gives a mean strain in the order of $30 \%$ for the surface composed of spherical asperities $\left(p_{m}=0.8 \mathrm{MPa}\right)$ and around $40 \%$ for the real road surfaces $\left(p_{m}=1.0 \mathrm{MPa}\right)$. Then the small strain assumption can become limited, but the contact results obtained with the model are coherent and may be a first good evaluation within the framework of tyre/road noise prediction.

\section{Experimental validation}

The purpose of this last part is to compare the numerical results of the TIM to tyre/road contact measurements in statics. The study is carried out for a slick tyre in contact with several road surfaces. First the measurement procedure is presented and experimental results are given. Then the adaptation of the input data of the model to the experimental contact configuration is described. The last part is concerned with the comparisons between experimental and numerical results.

\subsection{Measurements of tyre/road contact stresses in statics}

\subsubsection{Pressure measurement system}

Contact pressures and areas were measured using the digital pressure sensing device I-Scan ${ }^{\circledR}$ developed by Tekscan ${ }^{\circledR}$, which is reliable for the contact between moderate rough surfaces. The system is illustrated in Figure 5. It is composed of a matrixbased sensor linked to an acquisition card and a PC. The data acquisition display and analysis is monitored by software.

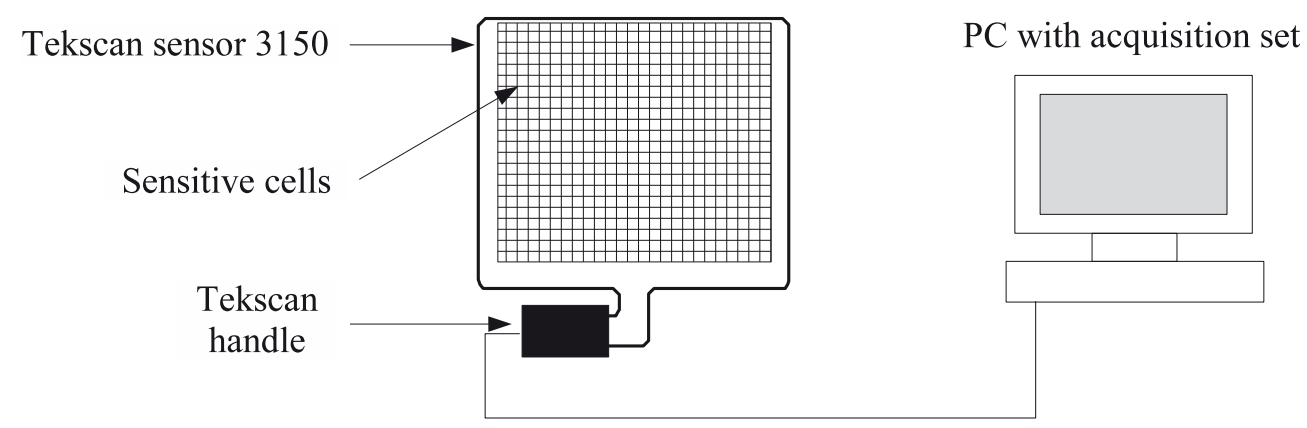

Figure 5. Schematic view of the pressure measurement system

The contact pressure distribution between two bodies can be measured in real time at a sampling frequency of $207 \mathrm{~Hz}$. The sensor consists in two thin and flexible polyester sheets which have conductive electrodes placed in a regular mesh. Between the sheets, a semi-conductive layer provides an electrical resistance that varies proportionally to the pressure applied. Thus, when placing it at the contact interface, the 
sensor is an array of pressure sensitive cells measuring the pressure distribution between the two surfaces. The sensor used in the experiment has the reference number 3150 . Its active area is a rectangle of $432 \mathrm{~mm}$ by $368 \mathrm{~mm}$ divided in an array of 2288 square sensitive cells of side $\Delta x=8.38 \mathrm{~mm}$. The sensor is very thin (thickness of 0.1 $\mathrm{mm}$ ) which minimizes the intrusion when placed between the two contacting bodies.

The measurement system provides raw data between 0 and 255 and a calibration must be applied in order to link these data with physical pressure values. The sensor response is not linear and depends on the sensitivity of the sensor, the geometry of the surfaces and the loading procedure. However, in a first approximation, the relation between the pressure and the digital values can be assumed linear around a given loaded configuration (Tekscan Inc., 2003). Thus, the manufacturer recommends to calibrate the sensor for a loading condition similar to the one in the measured case in terms of loading amplitude and duration. In practice, the total load $P$ applied on the tyre, measured independently on a weighting device, is used as the calibration reference on each measurement. Following this calibration procedure, the precision of the system given by Tekscan is $\pm 10 \%$ within the studied range. Additionally shear forces at the interface can damage the sensor or create noisy data, but such effects were not observed as only static contact was studied.

\subsubsection{Material and method}

The experimental setup for contact pressure measurement under static loading is shown in Figure 6. The tests were carried out on a passenger car fitted with two slick tyres on the rear wheels. Contact pressures were measured between the right rear slick tyre and several surface samples. The tyre was slowly and carefully loaded on the surface using a lift system for taking down the vehicle. The total load $P$ applied on the tyre was measured previously and was equal to $2950 \mathrm{~N}$. It was used for calibrating the sensor as explained above. Each measurement was repeated four times for better significance of the results.
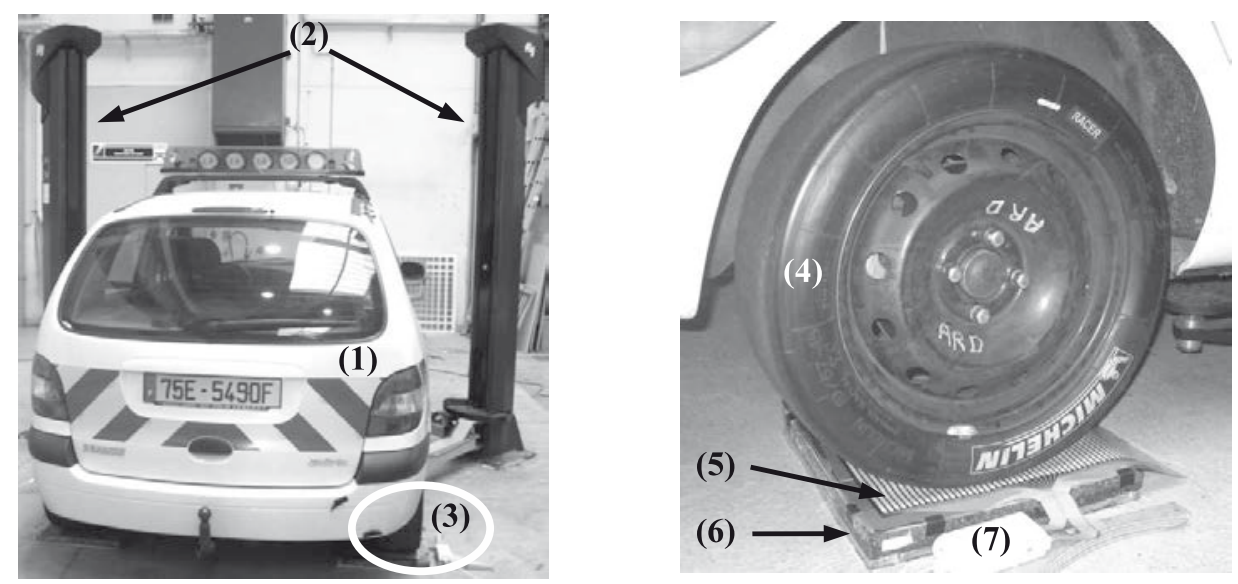

Figure 6. Experimental setup: (1) Vehicle, (2) Lift system, (3) Measurement area, (4) Slick tyre, (5) Tekscan sensor 3150, (6) Tested surface, (7) Tekscan handle 
Eight surface samples were used for the tests and can be seen on Figure 7. All surface samples are squares of $400 \mathrm{~mm}$ by $400 \mathrm{~mm}$. Two of them are model surfaces composed of spherical punches. The Model Surface 1 (MS 1) is made of spheres of radius $5 \mathrm{~mm}$ with a periodic honeycomb distribution. The Model Surface 2 (MS 2) is made of spheres of radius 4,5 and $6 \mathrm{~mm}$ with a random distribution. The other six surfaces are taken from real roads. One is a Smooth Epoxy (SE) surface. Three are asphalt concretes with $10 \mathrm{~mm}$ maximum aggregate size: a Dense Asphalt Concrete (DAC 0/10), a Thin Layer (TL 0/10) and a Porous Asphalt (PA 0/10). The last two surfaces are a Fine Surface Dressing (FSD 0.8/1.5) and Sand Asphalt (SA 0/4), both composed of small size protruding aggregates.

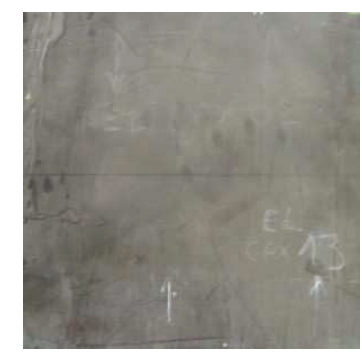

SE

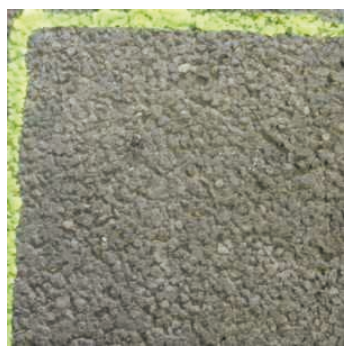

TL $0 / 10$

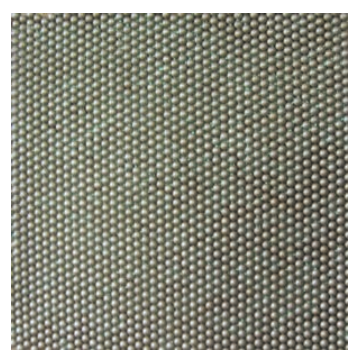

MS 1

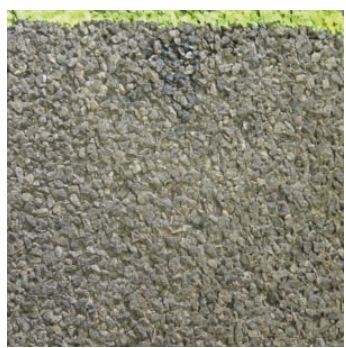

PA $0 / 10$

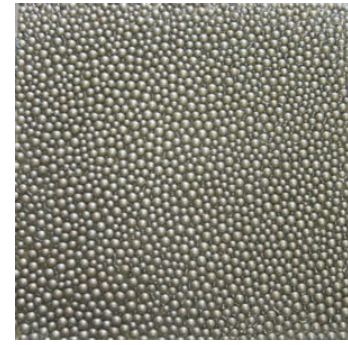

MS 2

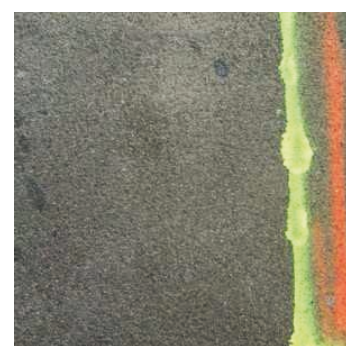

FSD 0.8/1.5

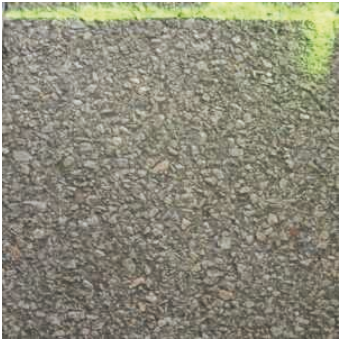

DAC $0 / 10$

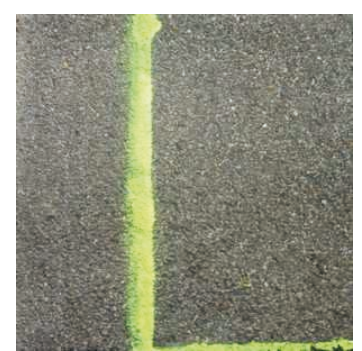

SA $0 / 4$

Figure 7. Upper view of the eight surfaces used for the tests

For all surface samples, the texture was measured in a rectangular area of $200 \mathrm{~mm}$ by $191 \mathrm{~mm}$ as described previously in Section 2.3. The contact tests were performed in this area in order to be able to compare the measured contact data with numerical results in the following.

\subsubsection{Measurement results}

Examples of measured contact patch are given in Figure 8 for surfaces MS 1, DAC $0 / 10$ and PA 0/10. The representation allows to visualize both pressure values and contact areas for a given surface. Each square colored element represents a cell of the Tekscan sensor. Pressure values range between 0 and $0.86 \mathrm{MPa}$, which is the saturation pressure of the sensor. The contours of the asperities of the surface are also represented in light gray for each sample.

For the model surface (MS 1), the periodicity of the asperities leads to a periodic pressure distribution. On surfaces with random texture, the pressure distribution is irregular. On the porous surface (PA 0/10) the measured pressures show more gaps in 

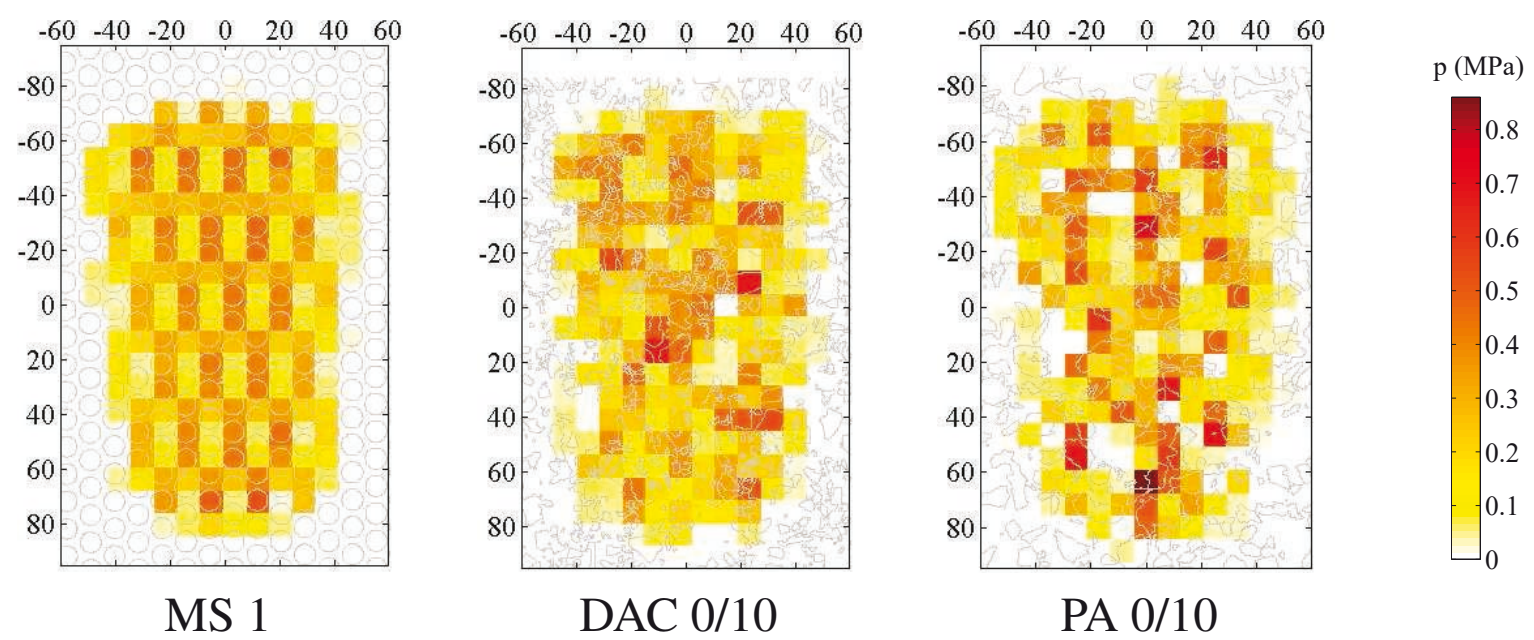

Figure 8. Examples of measured normal pressure distribution

the pattern (cells with a zero pressure) and higher maximum values than on the dense asphalt surface (DAC 0/10).

Due to the low spatial resolution of Tekscan sensor 3150, the real contact area on each asperity can not be identified in details. The pressure measured on a cell can be due to several asperities. Thus the total measured area, noted $A$, is closer to the apparent contact area than to the real contact area. For the eight tested surfaces, the total area was in the order of $135 \mathrm{~cm}^{2}$. It was larger in the transversal direction (around $15 \mathrm{~cm}$ ) than in the longitudinal direction (around $9 \mathrm{~cm}$ ). These results are in conformity with those of the literature for radial pneumatic tyres (Clark, 1981, De Beer et al., 2002). Additionally, the mean contact pressure, noted $p_{m}$, was around $0.22 \mathrm{MPa}$ which corresponds to the inflating pressure of the tyre.

\subsection{Adaptation of the contact model to the experimental setup}

\subsubsection{Multi-asperity description of each surface}

For each tested surface except the smooth one (SE), the measured texture was pre-processed as described in Section 2.3. The asperities were identified using the labelling procedure (Appendix A) and the five parameters $\left(X_{k}, Y_{k}, Z_{k}, C_{k}, \gamma_{k}\right)$ were obtained for each of them, allowing macro-scale calculation in the contact model.

From this pre-processing step, additional global parameters were defined for each surface. These are the mean distance and the mean relative height between the tips of the asperities, noted $\bar{r}$ and $\bar{h}$ respectively, the density, noted $d$, which corresponds to the number of asperities per surface unit and finally the mean values of the contact parameters $C$ and $\gamma$, noted $\bar{C}$ and $\bar{\gamma}$ respectively. Table 1 gives the global parameters obtained for each surface sample and their associated standard deviation (square root of the unbiased variance estimator, noted $\sigma$ ). 
Table 1. Global parameters and standard deviation obtained for the 7 rough surfaces

\begin{tabular}{cccccccc}
\hline Surface & MS 1 & MS 2 & DAC & TL & PA & FSD & SA \\
\hline $\bar{r}(\mathrm{~mm})$ & 14.65 & 14.16 & 13.24 & 13.22 & 13.48 & 13.22 & 13.22 \\
\hline$\sigma_{r}(\mathrm{~mm})$ & 4.08 & 3.79 & 4.70 & 4.72 & 4.47 & 4.69 & 4.68 \\
\hline $\bar{h}(\mathrm{~mm})$ & 0.03 & 0.04 & 0.37 & 0.44 & 0.69 & 0.22 & 0.18 \\
\hline$\sigma_{h}(\mathrm{~mm})$ & 0.02 & 0.08 & 0.27 & 0.34 & 0.58 & 0.16 & 0.16 \\
\hline$d\left(\right.$ asp./cm $\left.{ }^{2}\right)$ & 1.14 & 1.00 & 2.42 & 1.64 & 1.02 & 9.65 & 6.44 \\
\hline $\bar{C}$ & 2.85 & 2.94 & 2.38 & 3.13 & 3.00 & 1.52 & 1.97 \\
\hline$\sigma_{C}$ & 0.10 & 0.24 & 2.00 & 3.55 & 2.04 & 0.82 & 1.17 \\
\hline $\bar{\gamma}$ & 1.51 & 1.49 & 1.58 & 1.70 & 1.65 & 1.55 & 1.58 \\
\hline$\sigma_{\gamma}$ & 0.04 & 0.03 & 0.20 & 0.36 & 0.19 & 0.19 & 0.19 \\
\hline
\end{tabular}

The results show that the mean distance $\bar{r}$ between the asperities is in the same order for all the textures. The relative height $\bar{h}$ is very small for the model surfaces for which the tips of the spherical asperities are all in the same plane. For the road surfaces, the relative height increases with the size of the asperities and the porosity of the surface. The maximum relative height is found for the porous asphalt (PA 0/10). The density increases when the size of the asperities decreases, which is not a surprising result. Concerning the contact parameters, the results for model surfaces are in good agreement with the analytical values of $\bar{C}$ and $\bar{\gamma}$ expected from Hertz's theory for spherical asperities, which are respectively 2.98 and 1.5. For real road surfaces, the value of $\bar{C}$ increases with the size of the asperities and the values of $\bar{\gamma}$ show that the load-penetration function exponent globally ranges between 1 and 2, which are the extreme values obtained respectively in the case of a flat-ended punch and in the case of a conical punch.

These global parameters could be used as a first approach for the modelling of real road surface by asperities of simple geometry, on which the load-penetration function is analytically known. It could be also interesting to correlate these surface parameters with measured tyre/road noise levels in order to establish the influence of each parameter on noise emission. In a first step, the correlation of the parameters with the characteristics of the road surface could also be performed.

\subsubsection{Relative position of the tyre and the tested surface}

From the identified asperities, another difficulty was to perform the calculation at the same relative tyre/road position as during the tests. This corresponds to the position of the tyre frame $(O, x, y, z)$, noted $\mathcal{R}$, in the tested surface reference frame $\left(O^{\prime}, X, Y, Z\right)$, noted $\mathcal{R}^{\prime}$. The coordinates $\left(X_{0}, Y_{0}\right)$ of point $O$ were estimated from 
the coordinates of the experimental force center. These are different for each test and are calculated as follows:

$$
X_{0}=\frac{\Delta x^{2}}{P} \sum_{i=1}^{n} X_{i} \tilde{p}_{i} \quad \text { et } \quad Y_{0}=\frac{\Delta x^{2}}{P} \sum_{i=1}^{n} Y_{i} \tilde{p}_{i}
$$

where $P$ is the total load applied during the test, $\Delta x^{2}$ is the area of a sensor cell, $n$ is the number of loaded cells during the test, $\left(X_{i}, Y_{i}\right)$ are the coordinates of the cell $i$ in the frame $\mathcal{R}^{\prime}$ and $\tilde{p}_{i}$ is the measured pressure on the cell $i$. Thus the position of Tekscan sensor in the frame $\mathcal{R}^{\prime}$ has to be known for an accurate estimation of point $O$. This position is illustrated in Figure 9 and was carefully respected during the tests.

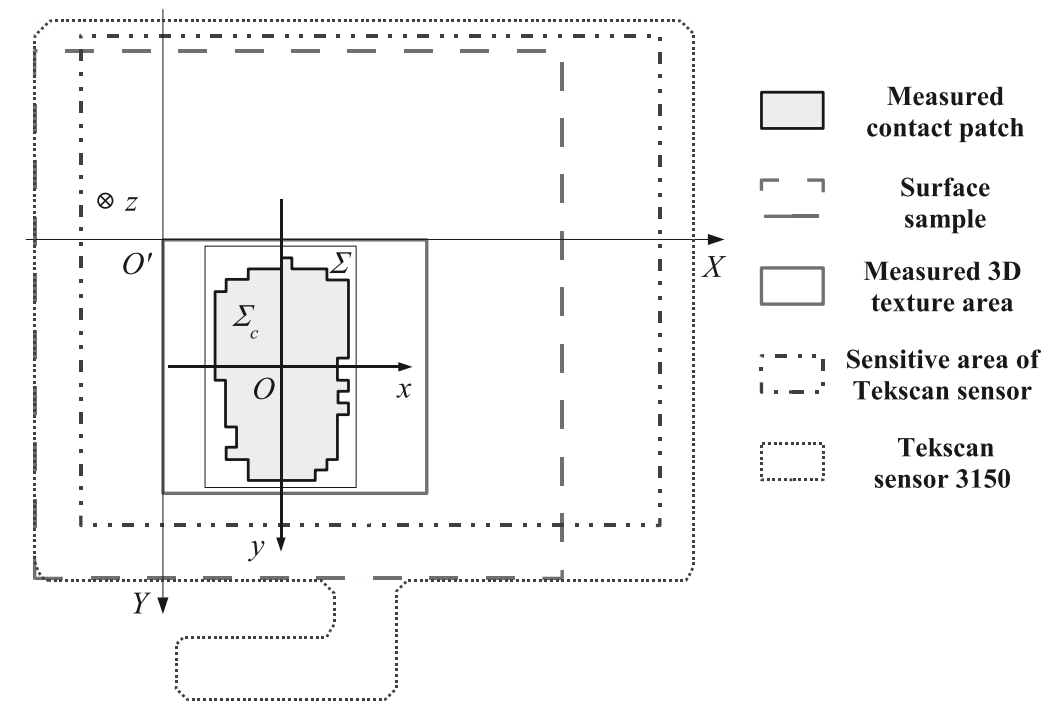

Figure 9. Position of the tyre in the road surface reference frame

Knowing the position of the tyre, the potential contact asperities are determined using a rectangular interest area centered around the point $O$ and noted $\Sigma$. The number of punches inside $\Sigma$ is noted $N$ and the contact model can be implemented using these asperities.

\subsubsection{Geometrical and mechanical parameters of the tyre}

The surface of the slick tyre $z_{t}$ was estimated from the revolution of a surface profile measured in the transverse direction with an optical device. The generated surface was added to the height of the road surface $z_{r}$, as described in Equation [4].

The equivalent Young's modulus of the elastic half-space was fitted from the contact between the slick tyre and the smooth surface (SE). The contact problem was numerically modelled using the MIM for a known total load $P$. The calculation was performed using square elements of side $0.5 \mathrm{~mm}$ and introducing the surface of the tyre in the model. The Poisson's coefficient $\nu$ was fixed to 0.5 , corresponding to incompressible rubber-like materials. The Young's modulus in the model was then adjusted in order to get the best agreement between the measured mean contact pressure and the one obtained with the numerical simulation. The result is illustrated 
Figure 10. The optimal Young's modulus is equal to 2.4 MPa. It gives a calculated mean contact pressure $p_{m}$ of $0.228 \mathrm{MPa}$, which is perfectly equal to the measured one. Let's remark that the calculated pressure distribution is perfectly symmetrical while the measured one is asymmetrical. This difference may be explained by an effect of the wheel suspension during measurements.
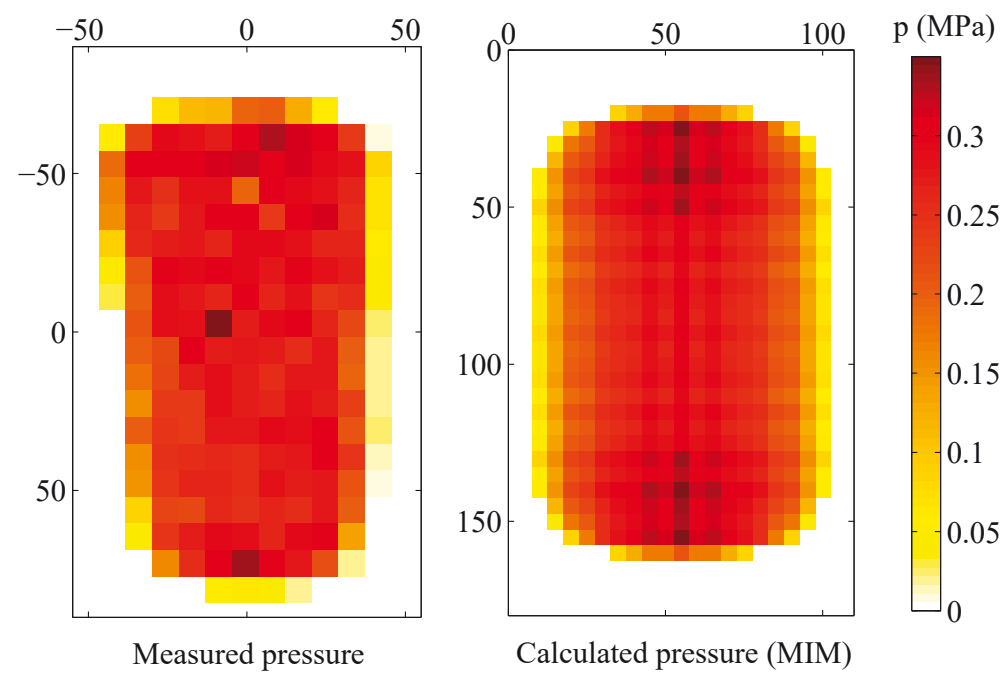

Figure 10. Estimation of the Young's modulus $E$ of the half-space by fitting the pressure distribution measured on the Smooth Epoxy surface (left) and the one calculated on a perfectly rigid plane surface (right)

\subsection{Comparisons between calculated and measured contact pressures}

\subsubsection{Integration of micro-scale calculation at Tekscan sensor scale}

Knowing input parameters, the TIM was implemented for each surface except for the smooth one. The calculation was performed at a fine scale $(h=0.4 \mathrm{~mm})$ and gave results similar to those presented in Section 2.3. Then the spatial resolution of the calculated results is very fine, whereas it is much wider for the measurement results (spacing of the sensor cell $\Delta x=8.38 \mathrm{~mm}$ ). Thus the micro-scale numerical results were integrated on surface elements equivalent to the sensor cells. Examples of calculated pressure distribution after integration at the sensor scale are shown in Figure 11 for surfaces MS 1, DAC 0/10 and PA 0/10. These results can be compared to the experimental data of Figure 8. It can be seen that qualitatively the agreement between measured and calculated prints is good. The periodicity of the model surface leads to similar periodic results in both cases. On surfaces with random texture, the calculated pressure distribution is still irregular. Higher maximum pressure values are found for the porous asphalt. This can be attributed to the relatively open texture of this road surface. The predicted contact areas are also similar to the measured ones. 

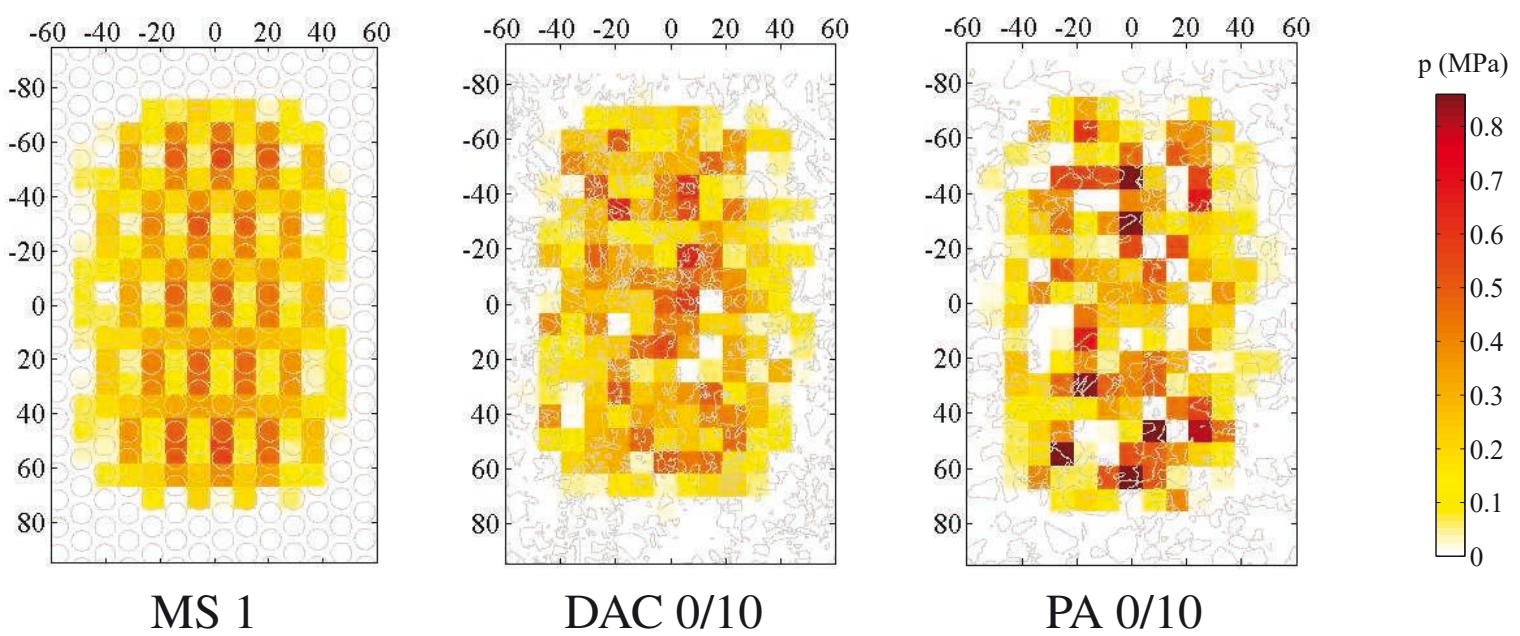

Figure 11. Calculated numerical pressure integrated at Tekscan sensor scale

\subsubsection{Correlation between global contact parameters}

The predicted and measured contact areas and mean pressures are compared for the eight surfaces in Figure 12. Each symbol corresponds to a road surface. The coefficients $a$ and $b$ of the regression line (solid line) are indicated together with the coefficient of correlation $\rho$. The dotted line is the one-to-one line. The agreement between predicted and measured data is qualitatively correct, especially when considering the accuracy of the measurement device (specified as $\pm 10 \%$ ). The predicted contact area is slightly underestimated in the case of porous asphalt and thin layer asphalt, leading to an overestimation of the mean pressure for these two surfaces. It corresponds to the two rougher surfaces.
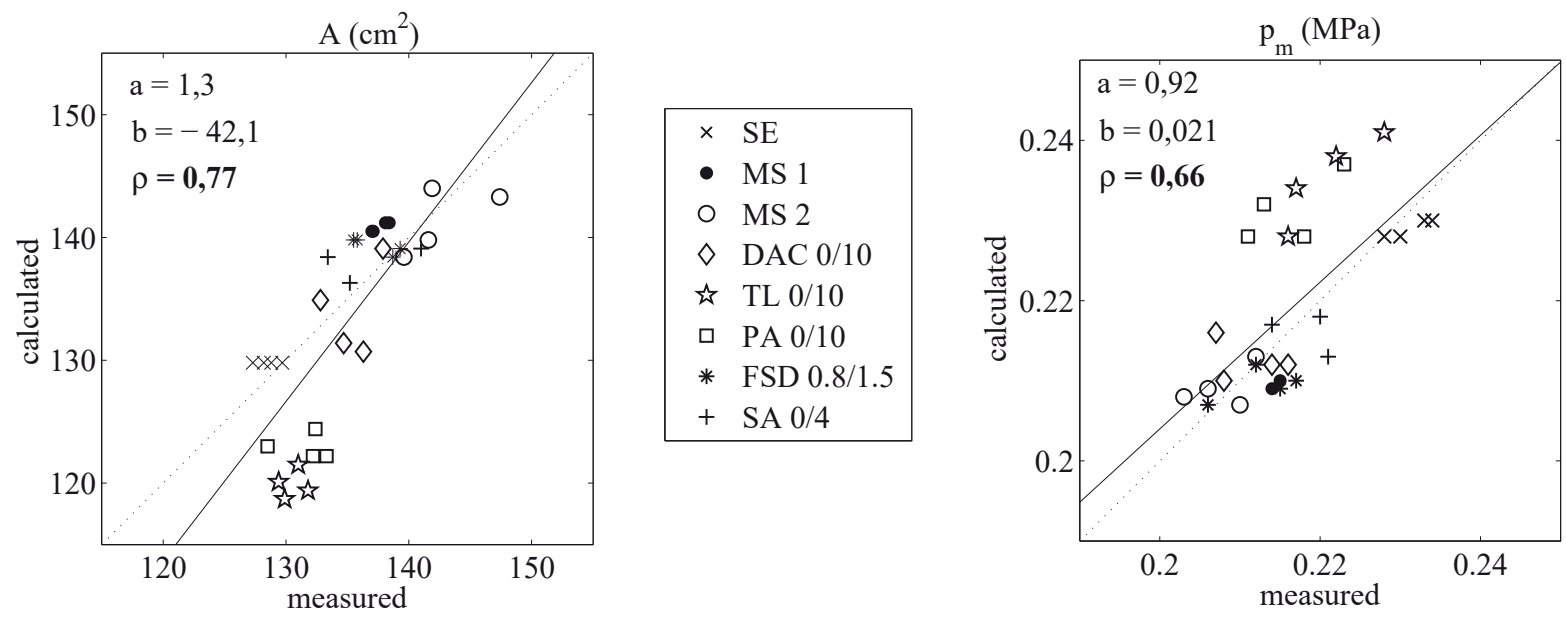

Figure 12. Comparison of calculated and measured contact areas A (left) and mean contact pressures $p_{m}$ (right) for the eight surfaces

\subsubsection{Correlation between contact pressure distributions}

For the seven rough surfaces, predicted and measured pressure values were compared in each area corresponding to a sensor cell. The results for surfaces MS 1, 
DAC 0/10 and PA 0/10 are displayed in Figure 13. The regression line is plain with coefficients indicated at the top left. The agreement is really encouraging since for these three examples the slope of the regression line is close to one and the regression coefficients are above 0.77 .

\section{MS 1}

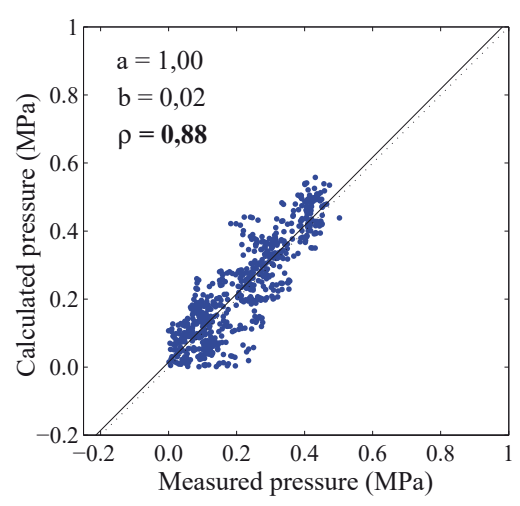

DAC $0 / 10$

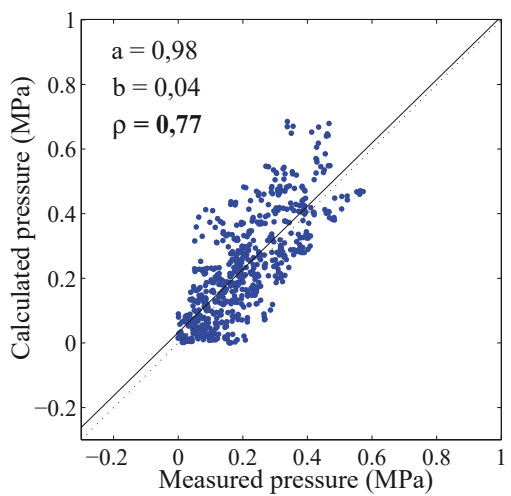

PA $0 / 10$

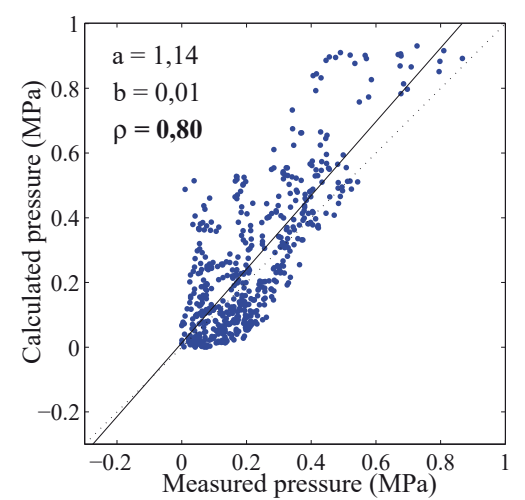

Figure 13. Comparison of calculated and measured pressure values

As it can be seen in Table 2, comparisons for other surfaces are of the same order, except for the last two surfaces due to a slight overestimation of predicted results at high pressure. These two surfaces (FSD and SA) correspond to relatively smooth surfaces with very small protruding aggregates inferior to $1.5 \mathrm{~mm}$ and for which the multi-asperity model can become limited at macro-scale.

Table 2. Correlation coefficient $\rho$ for the 7 rough surfaces

\begin{tabular}{cccccccc}
\hline Surface & MS 1 & MS 2 & DAC & TL & PA & FSD & SA \\
\hline$\rho$ & 0.88 & 0.82 & 0.77 & 0.73 & 0.80 & 0.53 & 0.59 \\
\hline
\end{tabular}

Globally, the differences observed can be attributed to small spatial shifts between the experimental and the modelled mesh. For high pressure values, the predicted results may be slightly overestimated in the case of very rough surfaces such as the TL $0 / 10$ or the PA $0 / 10$. This can be explained by the saturation of the sensor for local pressures higher than $0.86 \mathrm{MPa}$. Furthermore, the approximation in the calculation of the pressure vector $\mathbf{p}$ by local MIM may be inaccurate when several adjacent punches are seen by the penetrating tyre as one single punch.

\section{Conclusions}

In this paper, an efficient predicting approach for the modelling of normal contact stresses between a tyre and a rough surface in statics was presented and implemented. The resolution method of the contact problem, called the Two-scale Iterative Method 
(TIM), is much faster than other traditional methods. It makes possible the prediction of contact forces and pressures distributions on a surface with a large amount of punches, as it is the case for tyre/road contact.

An experimental validation of the model was performed by measuring contact pressure distribution in statics between a slick tyre and different surface samples, including real road surfaces. The input parameters of the model were carefully established from the contact configuration during the tests. The comparison between measurements and calculation is encouraging. A good agreement was found for the model surfaces composed of spherical punches and for the Dense Asphalt Concrete 0/10 with moderated macro-texture. The results are also good for the surfaces with high macro-texture such as the Thin Layer 0/10 and the Porous Asphalt 0/10. On the contrary, the measured and predicted data were poorly correlated for the Fine Surface Dressing 0.8/1.5 and the Sand Asphalt 0/4 with fine macro-texture. This may be explained by a limitation of the multi-asperity model when the surface is composed of very small protruding aggregates.

This study shows that road texture has a great influence on the tyre/road contact pressures in statics, which can be quantitatively predicted using the proposed contact model. Further developments will include the belt of the tyre in the model, for instance by calculating the influence matrix of the contact problem from the deformation of a tyre model including the belt and the tread. Future works will also address the dynamic measurements and calculation of tyre-road contact and the relations with the rolling noise emitted on different road textures. Further numerical developments will include friction in the model. This could enable to predict high frequency noise due to rubber friction during rolling. It would also extend the model for other applications where tyre/road contact is involved, such as skidding or rolling resistance. Finally, the viscoelasticity of the rubber and the vibration of the tyre structure during rolling could also be included in the model in the future.

\section{References}

Anfosso-Lédée F., Do M.-T., « Geometric descriptors of road surface texture in relation to tireroad noise », Journal of the Transportation Research Board - Assessing and Evaluating Pavements, Vol. 1806, 2002, p. 160-167.

Bijaoui A., Image et information : introduction au traitement numérique des images, Masson Ed., Paris, 1984.

Boussinesq J., Application des potentiels à l'étude de l'équilibre et du mouvement des solides élastiques, Gauthier-Villars Ed., Paris, 1885.

Cesbron J., Influence de la texture de chaussée sur le bruit de contact pneumatique/chaussée, $\mathrm{PhD}$ thesis, École Centrale de Nantes/Université de Nantes, 2007.

Clapp T. G., Eberhardt A. C., Kelley C. T., « Development and validation of a method for approximating road surface texture-induced contact pressure in tire-pavement interaction », Tire Science and Technology, Vol. 16, No. 1, 1988, p. 2-17. 
Clark S., Mechanics of pneumatic tires, US Departement of Transportation, National Highway Traffic Safety Administration, Washington DC, 1981.

De Beer M., Fisher C., Jooste F. J., « Evaluation of non-uniform tyre contact stresses on thin asphalt pavements », Proceedings of the $9^{\text {th }}$ International Conference on Asphalt Pavements, Copenhague, Danemark, August, 2002.

Fujikawa T., Koike H., Oshino Y., Tachibana H., « Definition of road roughness parameters for tire vibration noise control », Applied acoustics, Vol. 66, 2005, p. 501-512.

Hamet J.-F., Klein P., « Road texture and tire noise », Proceedings of Internoise 2000, Nice, France, 27-30 August, 2000.

Johnson K., Contact mechanics, Cambridge University Press, 1985.

Klein P., Hamet J.-F., Anfosso-Lédée F., « An envelopment procedure for tire/road contact », Proceedings of Surf 2004 - Symposium AIPCR sur les caractéristiques de surface de chaussée, Toronto, June, 2004.

Kropp W., Ein Modell zur Beschreibung des Rollgeräusches eines unprofilierten Gürtelreifens auf rauher Strassenoberfläche, PhD thesis, T. U. Berlin, 1992.

La Torre F., Domenichini L., Mancosu F., «Interaction pneu/chaussée dans le mécanisme de génération de bruit : résultats du projet TINO », XXI Congrès Mondial de la Route, Kuala Lumpur, 1999.

Sameur A., Modèle de contact pneumatique/chaussée pour la prévision du bruit de roulement, $\mathrm{PhD}$ thesis, École Nationale des Ponts et Chaussées, 2004.

Sandberg U., Descornet G., « Road surface influence on tire/road noise », Proceedings of the $9^{\text {th }}$ International Conference on Noise Control Engineering (Inter-noise 80), Miami, Florida, 8-10 December, 1980, p. 1-16.

Sneddon I. N., « The relation between load and penetration in the axisymmetric Boussinesq problem for a punch of arbitrary profile », International Journal of Engineering Science, Vol. 3, 1965, p. 47-57.

Tekscan Inc., I-Scan ${ }^{\circledR}$ - Equilibration and calibration practical suggestions, South Boston, 2003.

Wullens F., Kropp W., « A three-dimensional contact model for tyre/road interaction in rolling conditions », Acta Acustica united with Acustica, Vol. 90, 2004, p. 702-711.

\section{Appendix A. Algorithm for the identification of the asperities}

The algorithm for the identification of the asperities was developed by the authors using labelling techniques of image processing (Bijaoui, 1984). The procedure starts from the data of the measured surface, i.e. 955000 points of coordinates $\left(X_{i}, Y_{i}, Z_{i}\right)$. An asperity is characterized by a set of connected points above a given height $h_{0}$. A labelling algorithm is used as illustrated in Figure 14. First the measured surface is transformed into a binary image where the points above the height $h_{0}$ take the value 1 and the others the value 0 . Then from the binary image different groups of connected pixels are identified and the same integer, called label, is given to the pixels of the same group. Finally each labelled group corresponds to an asperity which tip of coordinates $\left(X_{k}, Y_{k}, Z_{k}\right)$ and load-penetration function can be identified. 


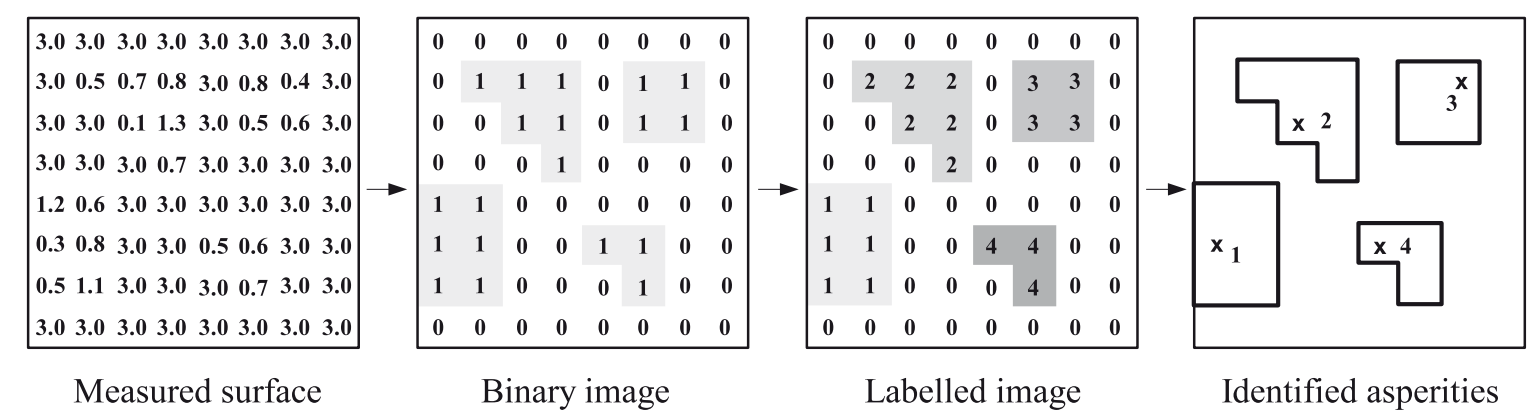

Figure 14. Labelling algorithm used for the identification of the asperities

An example of identification is given in Figure 15 for the DAC 0/10 road surface. For clarity, the results are given in a small area of $50 \mathrm{~mm}$ by $50 \mathrm{~mm}$ (right), but the asperities are detected on the whole measured surface (left). On the right figure, the crosses correspond to the tips of the asperities and the contours of the base of the asperities are also given.
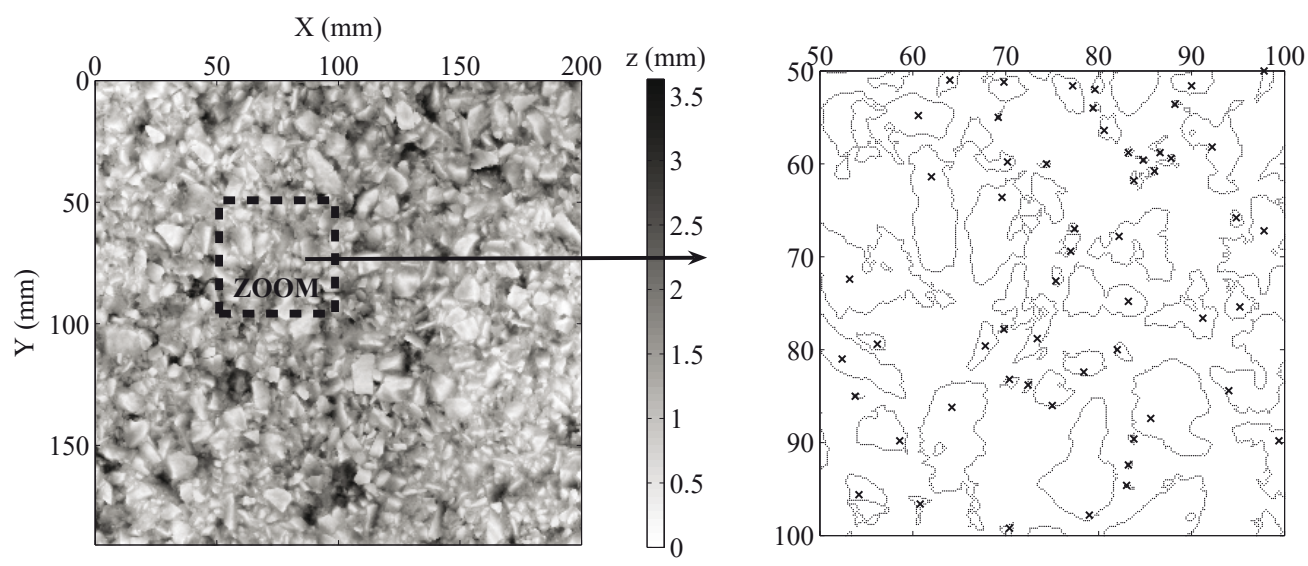

Figure 15. Example of identification of the asperities for the DAC 0/10

Concerning the time for identification, the measurement of the surface texture takes approximately 8 hours. Then the labelling procedure and the determination of parameters $C$ and $\gamma$ for each asperity takes less than one hour for each surface. This is done only one time and the results are saved for use in contact calculations. 